\title{
Conclusion
}

\author{
Learning from Loss
}

\section{LITTLE LESSONS}

We've visited a range of settings to address questions posed by Genji's queer gestures only to arrive at a provisional endpoint. These readings only scratch the surface of a vast area of inquiry into the relation between intimacy and loss, to say nothing of larger concerns regarding discipline and method. That said, several insights bear revisiting as this exploration ends. I'd therefore like to consider what we can learn from Genji's queering of intimacy and loss. Let's work backward.

Chapter 5 demonstrated how touch reverberates, discharging sensual repercussions irreducible to rational or intentional delimiting. Tactile engagement with the texture of objects undoes dominative styles of regarding the world. Melancholic fixations aside, touch grounds an altered self-regard that, unlike Yügiri's experience, needn't require self-abasement. If we forego his loathing, we might discover a beneficial humility through praxis. Musical instruments amplify Yūgiri's grief, but transposed to a different register, they might allow a generous reconsideration of his skill unburdened by regret. What might've happened had he not stopped playing? So let's play the music through and see if it doesn't lend some more viable perspective on the value of our lives and efforts. Not playing to recapture what has been irrevocably lost but rather playing to retrieve from the present less remorseful resources for thriving.

Chapter 4 examined how privation in exile can connect men physically, emotionally, and textually. Exile's punitive displacement from the Capital seeds a reparative potential for intersubjective and intertextual intimacies to take rootbeyond the domain of sexuality or textuality per se. Nourished by an oceanic expanse, the microaggressions germane to the paranoia of courtier life evaporate. One lesson here is that spatial and social constraints can foreclose capacities 
for creative modes of affiliation and artistry. Yet the energies generated through creative work reach leagues beyond the site of dislocation. Home, for all its comforts, swarms with quotidian restrictions. So when Tō no Chūjō heads home, he keeps turning to wonder what might bloom outside its confines. The recursive quality of this questioning compels me. Eroticism and longing fuel the gesture but can't delimit its momentum. This apprehensive gesture shows that Tō no Chūjō is no longer preoccupied with childish gotcha games and chiding that shroud loneliness and envy. Instructively, in Tō no Chūjōss departure from exile, we witness a will to power fade.

Suetsumuhana is my favorite character. Chapter 3 celebrates her beleaguered queer sensibility. Maybe it's my penchant for oddball underdogs, but I empathize with her and like her offbeat style. I appreciate the cadence of her living, which looks late only because haters loathe someone dwelling in the world in a manner heedless of the breakneck tempo of their own insecurities. Hence Chapter 3 is dedicated to the Suetsumuhanas of the world: all the folks out there trying to do their own thing and who aren't actually lost-despite the din that tries to drown out their contentment and convince them otherwise. Vernacular translation: "Haters gonna hate." So let them hate. Put their hatred to work; metabolize it. Let them do their jobs, then redirect that energy. If they whine, just remember: troll tears are delicious.

I was a Suetsumuhana once. I think of the bullies and bully wannabes who called me "faggot" growing up — not for being gay but for being smart. Intelligence was offensive because of White supremacist legacies we didn't comprehended because they so saturated the banality of Chicago life for us. That homophobia was normalized, sutured to racial and class-based formations we lacked conceptual and material tools to theorize or evade as children. I'm forty-one now, and some of those grade school classmates are dead. In this light, Suetsumuhana's lesson echoes as "Do you."

Chapter 2 recounts how Genji's machismo gets splintered, along with his ability to orient himself without admitting a debilitating awareness of his own contingency. Genji's aspirations for dominion are nipped in the bud as he gets lost and is rescued by his manservant. Genji learns the hard way not to let his reach exceed his grasp-especially when jealous spirits are involved. Although he ignores this lesson, "Yūgao" tells a cautionary tale, recommending against haughty incursions. Here, queer names a reoriented perspective and priorities, and a humbled acceptance of help in surviving the darkness.

Chapter 1 outlined contemporary queer theoretical interpretations alongside premodern accounts that both parallel and challenge modern assumptions regarding the politics of subjectivity, textuality, and disciplinarity. Here, queer and Genji become provocations to rethink our sense of both notions through a genealogical examination of their cultural assumptions, blind spots, and geopolitical baggage. 


\section{LARGER LESSONS}

These little lessons kindle larger questions. How does Genji queer? And where might queer readings of this text push the field of premodern Japanese literary studies? In the spirit of Ruthie Gilmore's definition of racism as "the state-sanctioned or extralegal production and exploitation of group-differentiated vulnerability to premature death," we might say that Murasaki Shikibu's text highlights the calibrated, disproportionate exposure of vulnerable bodies to privation and premature death. ${ }^{1}$ Whether it be Genji's mother, Kashiwagi, Yūgao, Aoi, Murasaki, or Genji himself, several protagonists suffer forfeitures of stature and vitality from micropolitical violences indebted to patriarchal domination. In response, Genji delineates necropolitical sinews striating the Heian body politic. The narrative queers by casting into radical doubt the logics perpetuating this system and by charting the depleting, often fatal violence through which it secures optimal function.

Genji queers to the extent that its fictional portrayals undermine the validity and trajectory of imperial authority. These depictions present Genji as a charismatic, deeply problematic product and perpetrator of violence shaped by imperial ambitions. The text queers by foregrounding the fictive, aspirational nature of normative and normalizing claims, giving the lie to systems that subsidize normalcy's enforcement. It deploys figures like Genji to interrupt facile notions of order, prompting readers to question dominant logics of family, romance, reproduction, power, movement, virtue, affection, striving, and feeling. To echo José Esteban Muñoz's gesture, Genji queers by refusing the finitude of the systemic inequalities that underpinned its circulation within Heian society.

The field of premodern Japanese literary studies could learn from such a refusal. For a queer impulse toward questioning pressures to conform applies not just to Genji's fictional realm but also to the actual world in which we undertake our intellectual work. We should therefore preserve a wary stance toward structures, tendencies, and rubrics whose investments in normativity (tacit or otherwise) dictate what questions get asked or don't - and by whom - to say nothing of how that questioning takes place. What then might be lost or gained by queering Heian literary studies? One risk would involve estranging familiar conceptual routines. Another would entail revising the perimeter of queer theory's comfort zone past a modern, Anglophone purview. Both risks deserve exploration through critical gestures that oppose the respective hermeticism of each territory.

This book can only pursue that project piecemeal. Granted, I'm more concerned about the fate of premodern Japanese literary studies than I am about the future of queer theory. But by the same token, those of us interested in attempting interventions in either field should locate ways to continue queering queer theory, by reminding it of other archives and experiences that fail-in conceptually generative ways-to align with activism, discrimination, legal discourse, or concerns with sexual identity, orientation, or preference that feel most familiar to us today. 
The goal would be to vitalize questioning, fostering a spectrum of perspectives rather than policing such views under the aegis of academic discipline-or, for that matter, rather than adopting a self-congratulatory progressivism whose conception of queer's utility has proved myopic in its presentist agenda. We'd lose the coziest claims to expertise but could gain insights whose value is not preordained.

To queer is to question the conditions by which — and price at which-affiliation, productivity, and evaluation occur. Queer inquiry remains dubious of protocols for producing instrumental knowledge, having no time for concerns tied to discipline for discipline's sake. To queer the discipline would be to avoid conventions trained on insular expertise to the impoverishment of more worldly discernment. Masao Miyoshi explains that "we are now experts rather than authorities. This difference is hardly trivial: an authority knows not only her/his specialty but also understands its place in the scheme of learning. An expert, on the other hand, is trained only in the field of specialization, and refuses to take even a step beyond it."2 A queer critical practice would sidestep this refusal to trespass in ways that ensured a less parochial sense of knowledge work's broader stakes.

If queer signifies an impulse to question systems of oppression enforcing explicit and unspoken injunctions to conform, then to queer Heian literary studies would be to interrogate not just the Heian texts themselves but also the parameters according to which the domain "Heian literary studies" directs textual analysis. The field could benefit from infusions of queer critical energy that proved generative precisely to the extent that it lacked aspirations to be productive; it had no craving to reproduce disciplinary routines that strove for closure. To queer would be to resist desires for conceptual fixity-or legacy.

It's because I'm cautiously optimistic for the future that it feels important to look back, like the protagonists Genji, Suetsumuhana, Tō no Chūjō, and Yūgiri do in their own queer ways. I think for instance about the serviceable role Japanese literature and Heian exemplars like The Tale of Genji played within a larger modern geopolitical context. Beyond the orientalist fantasies that flourished from the nineteenth century onward, the postwar context reprised this repertoire of tropes toward a different imperialist project. Namely, a focus on milquetoast texts distant from the nitty-gritty of an anticommunist battle for hearts and minds abetted a program of censorship whose legacy far outlasted the official departure of U.S. Occupation forces. Thus Kawabata's rhapsodies to Old Kyoto and Genji's portrayals of seasonal sensitivities and tapestries of romantic melancholy overshadowed more strident political works to help stem the tide of Soviet realism. To assure capitulation to American-style ideals, a more manageably benign brand of cultural production was advanced in service of liberal democracy and its capitalist patron.

As containment strategies aimed to suppress threats of resistance or revolution, this cultural agenda discovered fond fellows in Heian literature and other canons like it. Subsidized by government funding and deployed within the U.S. academy, these containment strategies entailed their own styles of supervision and neglect 
marked by Japanese studies' own penchant for certain brands of positivism and, historically at least, an allergy to theory. In contrast to the Marxist critical tradition that informed so much of European and other non-U.S. criticism, emphasis on close reading in the style of the New Critics attempted to sever texts' ties to their broader political contexts. Hence notions of passionate, pathos-filled Heian aestheticism upstaged other interpretive inclinations for decades. Whatever basis in reality such characterizations may have had, they nonetheless reflected Cold War desires for docile partnership that domesticated potentially subversive Japanese resonances. This "friendship" enforced a client-state hierarchy whose bliss remains as queer as the 1945 photograph of MacArthur beside Hirohito makes it look.

I wonder about the future of the field as the scholars central to its formative Cold War flourishing retire or die off. I also wonder about those students who gravitate away from premodern Japanese literature. Maybe it's because we haven't convinced them that the discipline is queer enough to merit their investment? And I don't mean in a cheap sensationalist way that barks "Sex! Samurai! Boy's Love manga!" Alternately, there are students who retreat to studying premodern Japan precisely because it promises sanctuary from the scarier world outside, with gauntlets of Japanese language bestowing bonus XP.

Regarding scary real-world matters, I also think about the students terrified to have "queer" show up on their transcript for fear of what questions it might raise. Whatever discursive damage the scholarly version of a paranoid hermeneutic might cause, its parental counterpart could prove far more damning for students. Parents' homophobia and sense of moral and economic value can make it difficult if not impossible for them to view such courses as worth spending tuition on. I'm not sure whether a queer studies course beats out a Heian literature course for Most Questionable Offering. However, it seems safe to say that within the context of burgeoning concerns within the contemporary university and society more broadly for securing a return on educational investment, both courses raise the question of value and prospective utility in threatening ways. Such courses not only precipitate potentially uncomfortable confrontations regarding students' sexual identity, they also out the students as frivolous, guilty of wasting time and money on ventures deemed unproductive according to a narrow, profit-based logic of productivity.

In the U.S. academy, at least, queer underscores a luxury already endemic in a less legibly utile field like premodern Japanese literary studies. Maybe Genji's masterpiece reputation helps, but within this economy the text signifies as queer in its ostensible failure to produce a recognizable impression of future payoff. It is under the banner of caring and responsible counsel that parents might dissuade students from entertaining such queer pursuits. More than any latent homophobia, the performativity of logics of futurity resurface to protect an imagined projection of children's employment prospects; for example, "But Angela, what about your future?!" The question of value underwrites a suppression of endeavors askew 
of seemingly sure bets. Come registration week, the Potential Employer looms like a boogeyman.

Not for everyone, though. For indeed, the perceived threat, distaste, or skepticism-or lack thereof-intersects gendered, regional, racial, and class constraints that shape course selection long before syllabi enter the picture. The choice of queerer topics predisposes itself to students whose backgrounds tend to allow for more risk. Class entitlement, in particular, would seem to grant students the most leeway, especially when graduating in efficient fashion feels crucial and course credits don't come cheap. Hence wealthier, Whiter students tend to enjoy a wider berth-a longer span to remain "undeclared" - and potentially suffer less fallout from making less economically rational choices.

One lesson here might be to deflect stigma by incorporating queer approaches into courses on premodern Japanese culture whose official titles needn't trigger paranoia. One could even take up the opportunity in such a course to discuss with students the nature of curricular, political, and affective constraints within the academy_-particularly as it relates to disproportionate distributions of vulnerability for folks marked as queer, colored, poor, and otherwise. Although no cakewalk, this kind of conversation could capitalize on latent paranoia to reparative effect. The result could be a critical sensibility grounded in more worldly awareness of how prejudice inflects what we study, how we learn, and how we perceive intellectual rigor and its risks.

\section{PARTING LESSONS: QUEERING THE CLOSURE OF EXPERTISE}

For all its investment in charting a kinship between intimacy and loss, A Proximate Remove tries not to forfeit disorientation's generative (and even pleasurable) potential. In this regard, I intend the book to be an intervention that queers an encounter with The Tale of Genji, to the benefit of our methods of critical intuition. My hope is that these readings arouse an awareness of our contingency-and of the limitations of our modern disciplinary expectations and investments-that does not instill horror but instead vitalizes our sensitivity to the fissures Genji's passages enfold. This seems worthwhile, if tough. Indeed, this very process of queering our apprehension of Genji might mean slowing down to rethink the disciplined stances we tend to take.

Considering the question of queerness within the context of medieval European texts, Carolyn Dinshaw stresses asynchrony as a temporal theme: "I explore forms of desirous, embodied being that are out of sync with the ordinary linear measurements of everyday life, that engage heterogeneous temporalities or that precipitate out of time altogether-forms of being that I shall argue are queer by virtue of their particular engagements with time." 3 For her, certain textual engagements demonstrate the collision of multiple temporalities within the now, attesting to 
the heterogeneity of the present. This occurs especially when "amateurs-fans and lovers laboring in the off-hours-take their own sweet time and operate outside of regimes of detachment governed by uniform, measured temporality; these uses of time are queer. In this sense, the act of taking one's own sweet time asserts a queer force. Queer, amateur: these are mutually reinforcing terms." ${ }^{4}$

Dinshaw's approach challenges reductive-and from a late-capitalist standpoint, cruelly productive-notions of time, also opening a space for altered relations to time that animate other modes of being. In theorizing proximate removes as queer gestures, my own readings of Genji here also highlight protagonists' desirous, embodied, out-of-sync-ness with surrounding regimes: Genji's horror at losing his bearings and feeling as though his male servant has taken a millennium to rescue him (chapter 2); the syncopation Suetsumuhana inserts into the standard love triangle's evolution (chapter 3); Genji's long span in exile, punctuated by Tō no Chūjōos fleeting visit (chapter 4); and Yūgiri's loitering with musical instruments his dead friend has abandoned (chapter 5).

What I also appreciate about Dinshaw's account is how, through praising amateur engagement, it questions rubrics of competency routinely taken for granted. This relates to larger disciplinary issues at stake when trying to study gender and sexuality in Heian cultural products. We should consider two contiguous interventions that accentuate Dinshaw's points: one in English literature and one in Heian literature; both literary and queer-explicitly or otherwise; and, serendipitously enough, both published in 1990. The first is Eve Sedgwick's Epistemology of the Closet, in which she endorses "the unrationalized coexistence of different models." Sedgwick had contemporary models of sex and gender in mind, but her stress of "unrationalized" attracts me. Models inhabiting yet not adhering to modern categories vexes knowledge workers much as it does the categories themselves. Opposing the prohibitive epistemologies designed to make queerness make sense, Sedgwick emphasizes plurality as part of a nonconformity to a modern, often oppressive heterosexist logic.

Sedgwick's recognition of the dangers of enforcing conformity to modern categories and desires for unifying clarity recalls the second intervention: Hideki Richard Okada's caution against domesticating The Tale of Genji. Taking issue with scholarly approaches to make sense of Genji either through a feminist project that highlights the tale's novelistic portrayal of "heroines" (Norma Field) or through insistence on its "poetic" unity (Haruo Shirane), Okada criticizes such moves as exclusionary and narcissistic:

Despite my remarks, naturalizing and domesticating representations of the Genji text based on expert referrals to secondary scholarship as demonstrated in [Field's] Splendor and [Shirane's] Bridge will seem to many the proper (if not the only) way of reading Genji monogatari. What I hope to have pointed out, however, is that without bearing in mind the exclusionary consequences of any attempt to preserve such traditional categories or disciplinary boundaries as the "literary" (with its requisite 
privilegings of the lyrical, the novelistic, or the heroic), your representation of the Other faces the prospect of turning into a variant of your own image. ${ }^{6}$

In Okada's reading, Field's and Shirane's frameworks, while expertly productive, nevertheless resort to comfortable categories that efface the text's queerest traces. His own preferred concept, "resistance," might commit a similar sin, though it likely curtails those traces less.7 Importantly, Okada's remarks bridge Dinshaw's interest in the queer forces discharged through amateurs' textual engagements with Sedgwick's preference for the "unrationalized coexistence of different models." Although Sedgwick was unfamiliar with Heian literature and Okada was unfamiliar with queer theory, both scholars oppose the naturalizing, exclusionary, and unduly unifying tendencies of a modern will to disciplinary knowledge. ${ }^{8}$ Although not explicitly focused on questions of gender or sexuality, Okada's skepticism toward "proper" ways of reading Genji nonetheless parallels Sedgwick's skepticism regarding unitary meanings and her advocacy for a queer "politics that values the ways in which meanings and institutions can be at loose ends with each other." 9 Moreover, Okada's critical posture evokes the queer force Dinshaw mentions, particularly as it touches the question of estrangement. As he notes, "In my experience, I have found that students are perfectly capable of re-situating themselves to handle what may at first seem alien; not only that, they are often quite willing to allow themselves and their received notions of 'literature' to be subjected to transformation in the process." 10

Note the turn to "students" here (cf. "scholars"). This turn matters as a critique of regimes invested in limiting styles of knowledge. Such investment can overpower an amateur's willingness to think and feel in more malleable ways than authorities tasked with edifying them would prefer. Okada invokes the figure of the student to question dominant models of academic authority, disciplinary rigor, and scholarly value-models that can, at their worst, twist the study of premodern Japanese culture into a suffocating enterprise for students and scholars alike. In this regard, Stefano Harney and Fred Moten's strong preference in The Undercommons: Fugitive Planning and Black Study for "study" over "knowledge production" resonates with Okada's suggestion. ${ }^{11}$ Okada's critique shuns the specious disciplinary assumptions governing how knowledge about premodern texts is normally produced and evaluated. If assailing these assumptions makes them "dissolve to reveal the shape of other, earlier categories, discourses, logics, coherences," then "the challenge facing Genji scholarship now would seem to be to find ways ... to make Genji strange, to read the non-excluded Other, rather than yet another version (no matter how well intended or documented) of ourselves."12

This notion of estrangement underscores the queer potential of reading Genji. Let's therefore append to queer's expanding resonances a notion of generative estrangement. The concept also returns us to queer's etymological roots as "strange," "not quite right," or "off-center." This is not to subsume or dismiss Genji's historical particularities under the veil of an untheorized strangeness. Rather, it 
is to reorient our sense of the text, our position toward it, and our presumptions about what it ought to reflect of its time-or our own.

Okada anticipates that Genjis "unconcern with closure may lead to conceptions of openness that complement contemporary notions of fragmentation or juxtaposition." ${ }^{13}$ Indeed, it is this "unconcern with closure" that continually returns me to the pleasures of thinking through Genji and that confers the transformative potential that students embrace in their "amateur," as yet only partially disciplined, engagement with it. Genji's unconcern with closure has most certainly induced centuries of expert inquiry aimed at disclosing its secrets. Yet that same unconcern could well authorize an inexpert method that allowed us to take our own sweet time to apprehend more amply the queer forces pulsing through it. To queer Genji would thus be to approach it from a proximate remove, estranging it in a generative fashion by incrementally posing questions toward the text that refuse finitude.

Regardless of one's feelings toward the term or its long-term analytic utility, queer, for the time being at least, helps me estrange The Tale of Genji in what I hope will be pedagogically affirmative, yet not definitive, ways. I embrace both the term and the text provisionally and intently. Despite the tale's distance, I continue to approach Genji as an inexhaustibly fascinating realm whose gravity proves too strong to release me from its orbit. So here's to the joys of long hauls and loose ends, to the incalculable cadence of study, unbeholden to any demand to produce knowledge. In the end, my hope is that these readings encourage students to imagine otherwise and pursue a reparative rapport with the text that, in a certain way, kindles light and heat for thriving. For to dwell with this Heian text's proximate remove from our own hostile world might teach us lessons lost within our present, lending us sustenance drawn from Genji's luminous unclosure. 